\title{
A numerical investigation on the performance of hydraulic fracturing in naturally fractured gas reservoirs based on stimulated rock volume
}

\author{
Ali Al-Rubaye ${ }^{1} \mathbb{0} \cdot$ Hisham Khaled Ben Mahmud ${ }^{1}$
}

Received: 29 May 2020 / Accepted: 7 August 2020

(c) The Author(s), corrected published 2020

\begin{abstract}
All reservoirs are fractured to some degree. Depending on the density, dimension, orientation and the cementation of natural fractures and the location where the hydraulic fracturing is done, preexisting natural fractures can impact hydraulic fracture propagation and the associated flow capacity. Understanding the interactions between hydraulic fracture and natural fractures is crucial in estimating fracture complexity, stimulated reservoir volume, drained reservoir volume and completion efficiency. However, because of the presence of natural fractures with diffuse penetration and different orientations, the operation is complicated in naturally fractured gas reservoirs. For this purpose, two numerical methods are proposed for simulating the hydraulic fracture in a naturally fractured gas reservoir. However, what hydraulic fracture looks like in the subsurface, especially in unconventional reservoirs, remain elusive, and many times, field observations contradict our common beliefs. In this study, the hydraulic fracture model is considered in terms of the state of tensions, on the interaction between the hydraulic fracture and the natural fracture $\left(45^{\circ}\right)$, and the effect of length and height of hydraulic fracture developed and how to distribute induced stress around the well. In order to determine the direction in which the hydraulic fracture is formed strikethrough, the finite difference method and the individual element for numerical solution are used and simulated. The results indicate that the optimum hydraulic fracture time was when the hydraulic fracture is able to connect natural fractures with large streams and connected to the well, and there is a fundamental difference between the tensile and shear opening. The analysis indicates that the growing hydraulic fracture, the tensile and shear stresses applied to the natural fracture.
\end{abstract}

Keywords DEM $\cdot$ Hydraulic fracture $\cdot$ Fractured gas reservoirs $\cdot$ Natural fracture

\section{Introduction}

Since its introduction, hydraulic fracturing has been established as the premier production enhancement procedure in the petroleum industry and has continued to overwhelmingly dominate low-permeability reservoirs as one of the most important field development operations (Rubin 1993). Achieving more production requires re-activation of the reservoir to increase permeability and raising the production of wells. Different phases of harvesting have a dramatic effect and because of the need to produce more hydrocarbon from unconventional reservoirs, reducing the flow of hydrocarbon fluid into the well (Tuffen and Dingwell 2005). Because of the well construction and low permeability of the reservoir

Ali Al-Rubaye

ali.rubaye38@gmail.com

1 Petroleum Engineering Department, Curtin University, Miri, Sarawak, Malaysia rock in some structures, especially in carbonate formations, it is necessary to use the methods of stimulation of the well (Gudmundsson and Brenner 2001; Bennion et al. 1996).

In very high permeability reservoirs, hydraulic fractures have a dual purpose: to stimulate the well and to provide sand control. In moderate permeability reservoirs, the fracture accelerates production without impacting the well reserves. In low-permeability reservoirs, hydraulic fracture contributes both to well productivity and to the well reserves, because in such reservoirs the well would not produce an economic rate without the hydraulic fracture (Pang et al. 2016). In homogenous reservoir with planar fracture geometry, there exists an optimum fracture dimension that would provide maximum reservoir performance for a given amount of proppant (Wei and Economides 2005). So predicting hydraulic fracture dimension by simulating hydraulic fracture propagation is crucial in hydraulic fracturing and completion design (Vinciguerra et al. 2004). Establishing hydraulic fractures in wells for 
various purposes, including creating a high-fluidity pathway to increase the well capacity capability, bypassing the damaged area around the well, connection of different reservoir layers in horizontal wells and in condensate wells, the gas wells are used to eliminate condensate accumulation (Vinciguerra et al. 2004; Wang et al. 2014).

The existence of natural fractures adds tremendous challenges to the hydraulic fracturing design. Since the introduction of the concept of stimulated reservoir volume (SRV) by Hahn et al. (2016), "complex network structures" has become a common postulation when we envision what hydraulic fracture really like in naturally fractured unconventional reservoirs. Besides indirect measurements and observations, such as microseismic monitoring, tiltmeter measurement and well interference analysis, that can be used to infer the upper bound of fracture dimension, it is extremely difficult, if not impossible, to quantify hydraulic fracture typology on a field scale (Zoback et al. 1977; Stanchits et al. 2011; Gandossi 2013).

Numerical modeling and simulation provide us an alternative to gauge the behavior of hydraulic fracture propagation in naturally fractured reservoir that cannot be substituted by small-scale laboratory experiment, where it is difficult to replicate in situ conditions with extremely high confining stress, in addition, the minimum stress tends to elevate (i.e., stress anisotropy can be much lower than designed or even disappear) during fracture propagation because of fixed displacement at the rock sample boundary (Malhotra et al. 2018), and the boundary effect cannot be fully eliminated even one can maintain a constant far-field stress field during fracture propagation, and on top of that, the impact of flow-resistance-dependent fluid distribution is not able to fully manifest itself in small-scale experiment, thus, laboratory experiment has the tendency to create hydraulic fracture patterns that are more complex than what is happening in the subsurface (Law and Curtis 2002; Reinicke et al. 2010).

The selection of the well and the candidate layer plays a significant role in the effectiveness of hydraulic fracturing operations (Montgomery and Smith 2010; Tan et al. 2018; $\mathrm{Ma}$ et al. 2016). In general, the purpose of selecting a candidate is selecting one or groups of wells or zones for operations that are most likely to succeed. Research has shown that if the choice of the well and the candidate layer is done well increasing production (Kranz et al. 1979; Nygord et al. 2006). Particularly in wells with high crustal and permeable coefficients, this can be significant. Most carbonate reservoirs have a low permeability; therefore, they can only produce economically, if they are hydraulically fractured (Davy et al. 2007; Bernier 2007; Kassis and Sondergeld 2010).

In this study, with the help of isolated and differential element methods, the modeling of the hydraulic fracture phenomenon and the study of the efficiency of this operation in one of the gas reservoirs in the south of Iraq has been investigated (Guo et al. 2013; Zhang 2013).

\section{Method}

The operation of hydraulic fracture in the naturally fracture gas reservoirs has some complications due to the presence of natural fractures. Various complex fracturing models of naturally fractured formations have been developed to describe the complex interaction mechanism between NFs and HFs, such as the boundary element method (BEM) (Goodfellow et al. 2015; David et al. 2018), discrete element method (DEM) (Gehne and Benson 2017; Benson 2004) and the finite element method (FEM) based on the cohesive zone method (CZM).

Simulation of hydraulic fracture operation in naturally fractured gas reservoir studied numerically and analytically, that due to the existence of natural fractures with different characteristics, it has complexity. The reactions that occur during hydraulic fracturing operations in the presence of natural fractures are very important in determining the efficiency of operations.

We used in this study finite difference fractions method and separate FALC software to simulate and analyze the interaction between hydraulic fracture and natural fracture in a naturally fractured gas reservoir. In addition, analysis for this work is done using the data obtained from the target gas field. For this purpose, in this study, two numerical methods are presented for simulating hydraulic fracture operation in naturally fractured reservoirs.

To evaluate the analysis in this study, the finite difference method, and the distribution of induced stresses around the well is simulated to determine the direction in which the hydraulic fracture is formed in that direction. After determining for the formation of a hydraulic fracture, using a separate element method, hydraulic fracture operations are simulated in a naturally fractured gas reservoir with different lengths, and in each case, the rate of production is examined. Inverse simulation, which is an important parameter and will reduce production in hydraulic fracturing operations, will be studied in this simulation. In each length of the hydraulic fracture, the rate of production is measured and the causes of changes in the input rate to the wells are discussed based on the natural fractures cut off by the hydraulic fracture and the alacrity of the fracture. Finally, the optimal hydraulic fracture condition will be when the hydraulic fracture can connect natural fractures with major currents and connect them to the well.

In this study, with the help of isolated and discrete element methods, hydraulic fracture operations were modeled in one of the naturally fractured gas reservoir in southern Iraq. To do this, first, using the finite difference method, 
the direction in which the fracture is created is determined. Then, by simulating the fractures around the well in the reservoir using a separate element method, a hydraulic fracture with different lengths in the reservoir and in the direction determined will be extended and the rate of production is provided. Additionally, at each stage, the number of natural fractures that will be cut off during the hydraulic fracture operation will be evaluated and discussed. The intersection of fracture and reverse suction phenomena that occurs in the interaction between the hydraulic fracture and the natural fractures in naturally fractured reservoirs are also considered and their effects on the production rate have been studied.

\section{Reaction between hydraulic fracture and natural fracture}

During the development of a hydraulic fracture in split reservoirs, there are three possible situations. The shape of various scenarios that may occur after collision between the natural fracture and the hydraulic fracture can be found in Fig. 1.

In the first place, natural fractures do not play any role, and the hydraulic fracture, in parallel with the direction of horizontal stress, will have maximum growth. This condition may be the result of high cement resistance in natural fractures (In comparison with matrix resistance), the improper orientation of natural fractures or inadequate deflection pressures to overcome the normal stress of the vertical natural fracture. In the second scenario, the hydraulic fracture breaks the natural fracture, trapped by a natural fracture, and the fluid is completely diverted into the hydraulic fracture. If the growth energy of the hydraulic fracture is sufficiently bigger than the normal opening fracture of the cements, or,

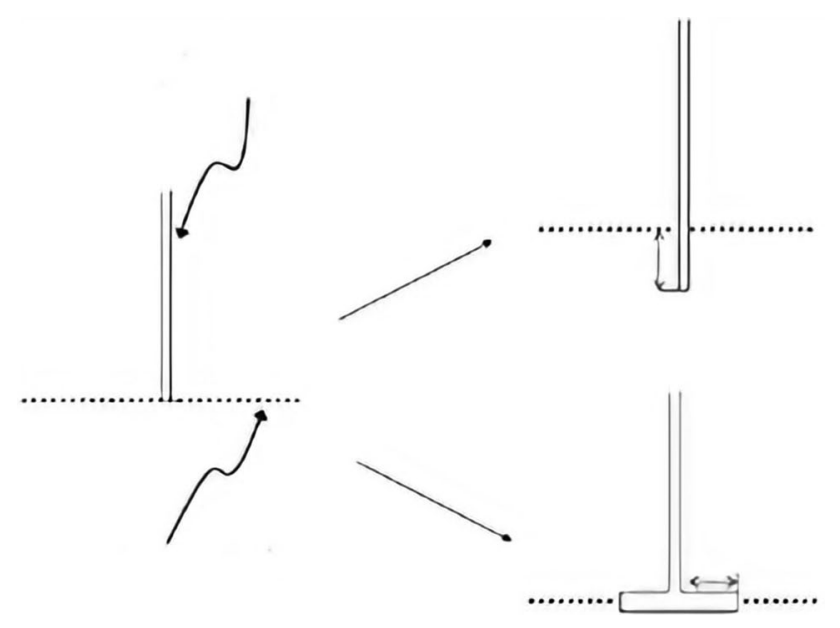

Fig. 1 Various scenarios after collision between natural fracture and hydraulic fracture if the shear stresses of the hydraulic fracture are so high that they overcome the stiffness between the levels of the natural fracture, natural fractures will be opened. In the last scenario, natural fractures in a situation where specific complexity is interrupted by a hydraulic fracture. Debonding the natural fracture in front of the hydraulic fracture (before being cut off by it) is also one of the important phenomena in the reaction between the inductive and natural fracture. In other cases, the natural fracture begins to open, cut, or grow before the hydraulic fracture collides with it. The reason for this phenomenon can be the concentration of tensions near the tip of the fracture (Goodfellow et al. 2015). If such a phenomenon occurs, even if the hydraulic fracture is diverted into the natural fracture, the natural fracture can be shaped like a double. In this scenario, if the natural fracture has a high degree of heterogeneity from the tensile point of view, it may prevent the growth of the hydraulic fracture.

\section{Methods used}

\section{Finite difference numerical method}

The finite difference of mathematical expressions is $f$ $(x+b)-f(x+a)$. If a finite difference is split into $b-a$, then we will have a different division. The approximation of derivatives in the finite difference plays an important role in the finite difference methods for the numerical solution of differential equations, especially boundary-value problems. Certain recurrence relationships can be written as differential equations by replacing repeating symbols with finite difference. Today, the term "finite difference" is used as the synonym for the derivation of finite difference, especially in the field of numerical methods. The finite difference approximation, in fact, is the same outside of the differential divisions in the terminology used above (David et al. 2018; Gehne and Benson 2017; Benson 2004).

Finite difference method (FDM) is one of the numerical methods for solving the approximate differential equations. In this method, the derivatives of functions with their equivalent differences are approximated. The basis of this method for solving equations is using the Taylor method to approximate the function. For the approximation of the function $f$ at $x_{0}+h$, we use the Taylor expansion:

$f\left(x_{0}+h\right)=f\left(x_{0}\right)+\frac{f^{\prime}\left(x_{0}\right)}{1 !} h+\frac{f^{2}\left(x_{0}\right)}{2 !} h^{2}+\cdots+\frac{f^{(n)}\left(x_{0}\right)}{n !} h^{2}+R_{n}(x)$

Then, for $x_{0}=a$ and split sides on $h$ and for the approximation of the function $f$ at $x_{0}+h$, we use the Taylor expansion: 
$\frac{f(a+h)}{h}=\frac{f(a)}{h}+f^{\prime}(a)+\frac{R_{1}(x)}{h}$

As a result, we have:

$f^{\prime}(a)=\lim _{h \rightarrow 0} \frac{f(a+h)-f(a)}{h}$

In a finite difference method, a suitable approximation for this function will be:

$f^{\prime}(a) \approx \frac{f(a+h)-f(a)}{h}$

First, to determine the direction of the hydraulic fracture, we need to distribute the stresses around the well. For this purpose, a finite difference method was used. This method is characterized by a finite difference code that simulates the behavior of structures composed of soil, rock and materials, which, when they reach a degree of flexibility, may exhibit plastic behavior. Each component employs a stress-strain relationship a nonlinear or linear strain in response to the force input and boundaries. If the tensions are large enough, it causes the flexibility and shape of the material, in which case the network will actually be transformed and moved. This form is called the Lagrangian calculation problem, and for modeling, the changes include an intermediate model. A finite difference method is also used to simulate the continuous behavior of the individual regions of the sloping surfaces, the presence of separate faults or joints within a single or separate or sloping region.

Underground formations are often subjected to tensile stresses or tensile stresses or other tectonic factors. When excavated in a well form, due to the lack of rock space to withstand earth tensions, the well wall is maintained only by the fluid pressure inside it.

With respect to the minimum and maximum horizontal tensions in the cylindrical coordinates, according to the rules of the Kirsch equations, for a vertical well which is centered on the main stresses, tensions around the well are expressed as follows (Gehne 2018):

$$
\begin{aligned}
\sigma_{\mathrm{r}}= & \frac{\sigma_{\mathrm{H}}-\sigma_{\mathrm{h}}}{2}\left(\frac{1-r_{\mathrm{w}}^{2}}{r^{2}}\right) \\
& +\frac{\sigma_{\mathrm{H}}-\sigma_{\mathrm{h}}}{2}\left(1+3 \frac{r_{\mathrm{w}}^{4}}{r^{4}}-4 \frac{r_{\mathrm{w}}^{2}}{r^{2}}\right) \cos 2 \theta+p_{\mathrm{w}} \frac{r_{\mathrm{w}}^{2}}{r^{2}} \\
\sigma_{\theta \theta}= & \frac{\sigma_{\mathrm{H}}-\sigma_{\mathrm{h}}}{2}\left(\frac{1-r_{\mathrm{w}}^{2}}{r^{2}}\right)-\frac{\sigma_{\mathrm{H}}-\sigma_{\mathrm{h}}}{2}\left(1+3 \frac{r_{\mathrm{w}}^{4}}{r^{4}}\right) \cos 2 \theta-p_{\mathrm{w}} \frac{r_{\mathrm{w}}^{2}}{r^{2}} \\
\tau_{\mathrm{r} \theta}= & -\frac{\sigma_{\mathrm{H}}-\sigma_{\mathrm{h}}}{2}\left(1-3 \frac{r_{\mathrm{w}}^{4}}{r^{4}}+2 \frac{r_{\mathrm{w}}^{2}}{r^{2}}\right) \sin 2 \theta
\end{aligned}
$$

In these equations, " $\sigma_{\mathrm{r}}$ " is the effective stress in the radial direction, " $\sigma_{\mathrm{H}}$ " is the maximum horizontal stress, " $\sigma_{\mathrm{h}}$ " is the minimum horizontal stress, " $r$ " is the well radius, " $r$ " is the study radius, " $p_{\mathrm{w}}$ " is the pressure inside the well, " $\sigma_{\theta \theta}$ " tangential stress, " $\tau_{\mathrm{r} \theta}$ " is the shear stress and " $\theta$ " is the maximum angle with respect to horizontal stress.

As shown in Fig. 2, fluid pressure is often not consistent with tensions, which can cause tensions to collapse around the well.

In order to minimize stress azimuth, tensile stress has increased greatly and in the direction of azimuth of maximum stress, the tensile stress has reached its lowest level. Therefore, by increasing the internal fluid pressure of the well, according to Eq. 2, there is the possibility of creating and extending the crack for the azimuth of maximum stress.

Unlike breakout of the well wall, when the permeability stress of the well is more than the resistance of the rock and is due to the pressure stress of the well wall, the breakout of hydraulic fracturing is due to tensile stress and a $90^{\circ}$ angle to the direction where breakout is possible. Since the work done to open defect the gap (which is caused by the tensile force applied perpendicular to the slit plane at the opening rate), the stress is minimal (Fig. 3) in this direction and the least energy is consumed.

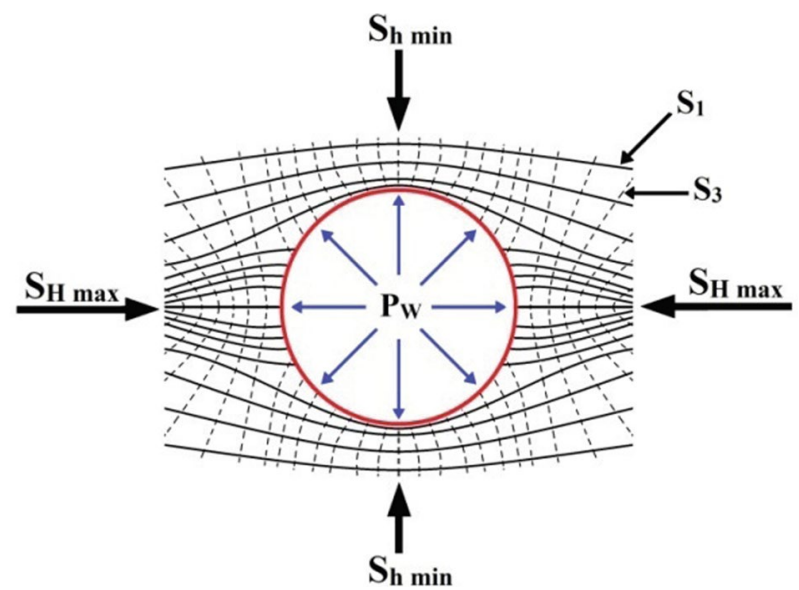

Fig. 2 The path of the main stresses around the well based on the Kirsch equations (the well wall is a free surface, and the well axis is in the direction of vertical stress)

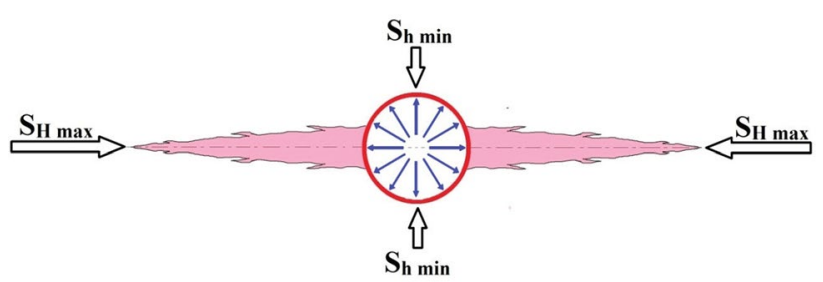

Fig. 3 Creating a perpendicular fracture for minimum stress 
According to linear elastic theory, when the tensile stress at the tip of the slit reaches the tensile strength of the rock, the fracture begins to progress. Of course, it should be noted that the linear elastic hypothesis is used only for large-scale fractures. Afterward, the fracture extends vertically onto the plate perpendicular to " $S_{\mathrm{h}}$ ".

The minimum pressure known to cause a fracture in the well wall and known as the $\left(p_{\mathrm{f}}\right)$ start-up pressure is given by the following equation:

$P_{\mathrm{f}}=\frac{T+3 \sigma_{22}-\sigma_{11}}{2-\alpha\left(\frac{1-2 \theta}{1-\theta}\right)}+p_{\mathrm{o}}$

In cases where the fluid is impenetrable, the total stress of " $S_{\theta \theta}$ " is changed as follows:

$S_{\theta \theta}=\sigma_{\theta \theta}+P_{\theta}=3 \delta_{22}-\sigma_{22}-\sigma_{11}+P_{0}-P_{\mathrm{w}}$

In the above relations, " $p_{\mathrm{w}}$ " is the fluid pressure difference, " $P_{0}$ " is the pore pressure of the fluid in the formation, " $\sigma_{\theta \theta}$ " of the effective tensile stress, " $T$ " is the tensile strength of the stone, " $U$ " Poisson ratio, " $\alpha$ " is the bite factor, " $\sigma_{11}$ " and " $\sigma_{22}$ " are, respectively, the maximum and minimum stresses.

\section{Discrete element method}

A discrete elemental method, or "DEM," is one of the numerical methods for calculating the interactions of a large number of small particles. Despite the very close relationship between DEM and molecular dynamics simulation, features such as the degree of rotational freedom (rotational), the particle contact and complex geometry distinguish this approach in general with other options.

With the development of computing power and the development of numerical algorithms for sorting by the nearest neighbor method, it was possible to simulate millions of particles by employing only one processor. Today, the acceptance of the discrete elemental method is growing as an efficient approach to solving engineering problems in discontinuous and materialized environments such as rock mechanics, powdery material mechanics, material flow. Considering the thermodynamic principles of DEM and its combination with computational fluid dynamics (CFD), DEM, the extended discrete element method, or so-called XDEM, has been developed in recent years.

\section{The overall process discrete element method}

Simulation of the DEM begins by creating a model, determining the location of all particles and assigning the initial speed to each of them. Calculation of the forces applied to each particle with the help of initial data, physics rules and models related to the surface of the contact.
Usually to reduce the number of common contact surfaces and computational power required, a sorting process is used by the closest neighbor method in the step of determining the time. This process often takes place within certain timeframes.

Discrete element method is a two-dimensional numerical analysis method that is considered for the analysis of rock mechanics of discontinuous environments. By this method, it is possible to simulate the reaction of a discontinuous medium (such as tectonized and highly bonded) to static and dynamic loads. This method defines a rock environment as a set of discrete blocks in which discontinuities (such as joints) act as boundary conditions between blocks and shear displacements can be done along these discontinuities as well as rotation of the blocks. In this method, it is possible to define the blocks in rigid and ductile form. Modifiable blocks are divided into a network of elements with a finite difference, and each element acts with predetermined linear or nonlinear strain-strain behavior.

\section{Reservoir studied}

South of Iraq is known as one of the most important hydrocarbon reservoirs in the world. Although the geological position of this area is well known, it is still not well known how the hydrocarbons from the different fields are. The gas field that we study in this research paper is located in Basra governorate, $30 \mathrm{~km}$ south-east of Basra city. It is reserved about $1.1 \mathrm{tcf}$ gas. The size of the field is approximately $21 \mathrm{~km}$ long and $6-13 \mathrm{~km}$ wide.

The most important and comprehensive research on the dispersion of the origin and maturation stones of the gas produced in the reservoir formation of this gas field using carbon-isotope, sulfur and biomarkers.

\section{Geological location}

In this study, we evaluated the gas reservoir. Using lithologic columns drawn from wells in the field, the longitudinal section was drawn to stratigraphic adaptation. The zoning carried out on the above section shows that this gas reservoir consists of 4 zones consisting of A, B, F and $\mathrm{E}$ formations. Major areas of interest include zones F, and $\mathrm{E}$. Among these zones, zone $\mathrm{E}$ with a facade that is clean and dolomitic has the highest reservoir quality and the largest share of production from the reservoir. Also, the results of petrophysical assessments show that the upper parts of reservoir formation compared to its main section have better conditions for reservoir quality. The central area of the field, which has the highest thickness, with proper fractures due to the elongation of the upper part of the formation, it has a high potential for

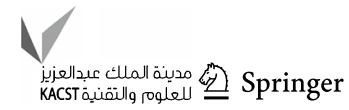


field gas production. According to the results of this study, the north of the well No. 4 for the withdrawal of the reservoir with the zone $\mathrm{E}$ is the best region for future drilling.

\section{Results}

In this study, using discrete element and finite difference methods, hydraulic fracturing operations were modeled in one of the naturally fractured reservoirs in southern Iraq. To do this, first, using the finite difference method, the direction in which the fracture is created is determined. Then, by simulating the clefts around the well in the reservoir using a discrete element method, a hydraulic fracture with different lengths in the reservoir and in a predetermined direction will extend along the length of the production rate. Additionally, at each stage, the number of natural fractures that will be cut off during the hydraulic fracture operation by the fracture will be evaluated and discussed. The intersection of gap and reverse suction phenomena that occurs in the interaction between hydraulic fracture and natural fracture in naturally fractured reservoirs are also considered, and their effects on production rates are investigated.

\section{Numerical results}

In this section, we will look at the methods used (discrete element and finite difference), which we will continue to discuss.

\section{Finite difference method}

In this section, in order to investigate the interaction between the hydraulic fracture and natural fractures, only fractures that are about $45^{\circ}$ to the hydraulic fracture are desirable; Because, as can be seen from the previous method, most of the natural fractures that are cut off by the hydraulic fracture are about $45^{\circ}$ angular natural fracture. The hydraulic fracture, when approaching the natural fracture with a $45^{\circ}$ angle, causes it to dry before the natural fracture is debonding. In the natural fracture, there are two types of tensile and shear debonding that vary in different areas of the natural fracture (Sammonds (1999); Jones et al. (1998); Benson et al. (2010); Fazio et al. (2017); Walsh (1981); Kneafsey et al (2018)). In this section, the failure caused by the progress of the hydraulic fracture occurs according to Fig. 4 in three regions $\mathrm{a}, \mathrm{b}$ and $\mathrm{c}$.

The graph of tensile and normal opening is shown in Fig. 5.

When the hydraulic gap reaches the a region, the tensile fracture is almost normal; in this way, the midpoint of the natural fracture (the intersection point or the area of the

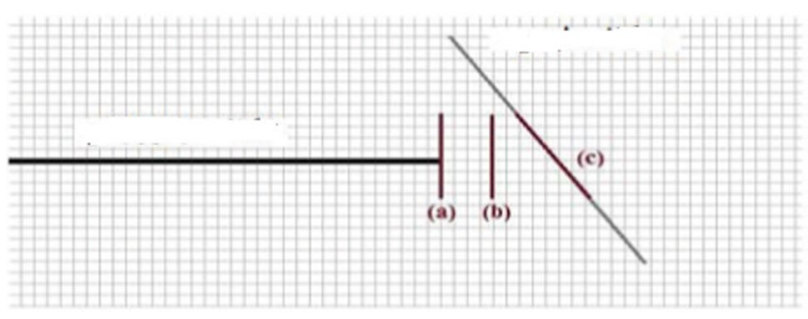

Fig. 4 A schematic of the position of the natural gap relative to the hydraulic gap in the three regions $\mathrm{a}, \mathrm{b}$ and $\mathrm{c}$
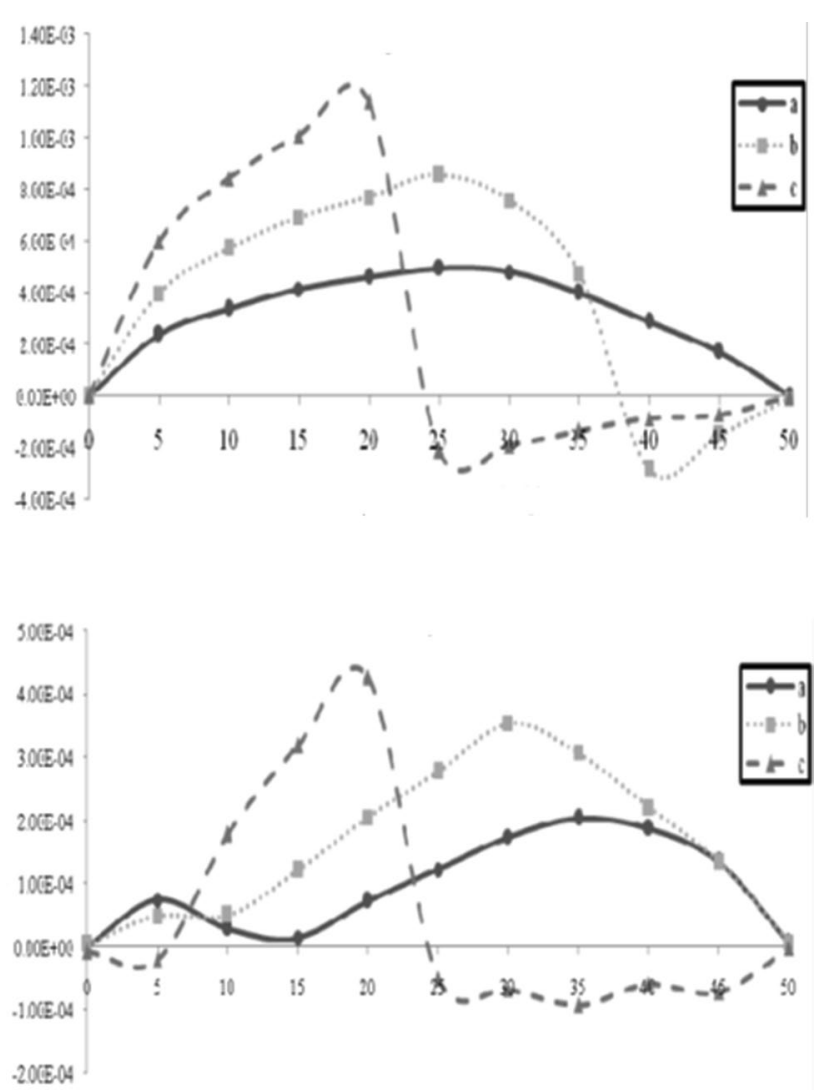

Fig. 5 Tensile and shear displacements in specified areas

natural fracture that passes through the progressive hydraulic fracture) takes the greatest amount of opening. As the hydraulic fracture reaches the area $b$, the situation will be slightly different because, despite the highest opening at the intersection of the two fractures, this time the upper part of the natural fracture is denser. This becomes noticeable when the hydraulic fracture reaches the natural fracture (point c). The upper part of the natural fracture is dense, and the lower part is open.

In the case of shear failure, with the achievement of the hydraulic fracture to a, there is no longer symmetric opening, but there is a displacement peak in two regions. In area 
$\mathrm{b}$, this situation is more perceptible. Carefully, it can be deduced from the diagram that with the closeness of the hydraulic fracture, the maximum shear opening from the upper regions of the natural fracture to the lower parts is changing. By reaching the natural fracture (area c), this inference appears to be somewhat correct; because the cutoff peak occurs at the bottom of the natural fracture. In fact, in order to move the two plates, the natural fracture is in the upper and lower directions.

In both tensile and shear joints, the least amount of opening is related to the nodes of the natural fracture or close to it; because the tensions are concentrated in a fracture at its tip. In the case of the tensile and shear opening phenomena induced by the hydraulic fracture in the natural fracture, discussed above, the state of stress was assumed to be isotropic. Figure 6 shows the distribution of induced stresses around the well using a finite difference method.

If the well is in equilibrium, that is, the pore pressure " $P_{0}$ " and the " $P_{\mathrm{W}}$ " well pressure are equal to each other. Considering that based on the available data from wells, " $S_{\mathrm{H}}$ " is $44 \mathrm{MPa}$, " $S_{\mathrm{h}}$ " is $40 \mathrm{MPa}$ and " $S_{\mathrm{v}}$ " is $87 \mathrm{MPa}$. Therefore, the minimum and maximum inductive stresses will be 76 and $92 \mathrm{MPa}$, respectively. As shown in Fig. 7, these points, which are simulated by the finite difference method, also represent approximately the same numbers. Determining the position of the minimum and maximum induced stresses will determine the direction in which the hydraulic fracture will propagate. The fracture will be formed in the direction of maximum induced stress. The alignment of the hydraulic fracture is shown in Fig. 7.

\section{Discrete element method}

After determining the direction of the hydraulic fracture, the situation of the fracture between the wells is simulated

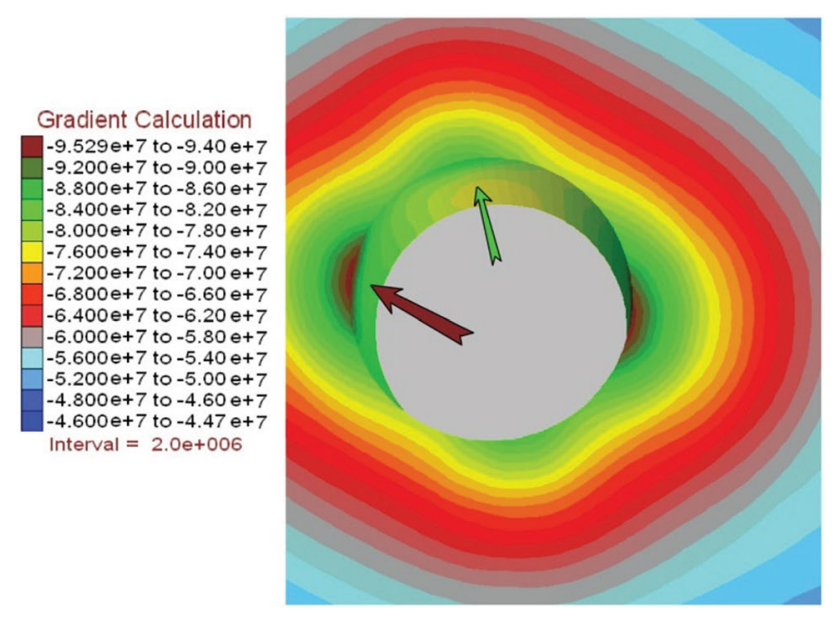

Fig. 6 Status and position of minimum and maximum induction stresses on well walls

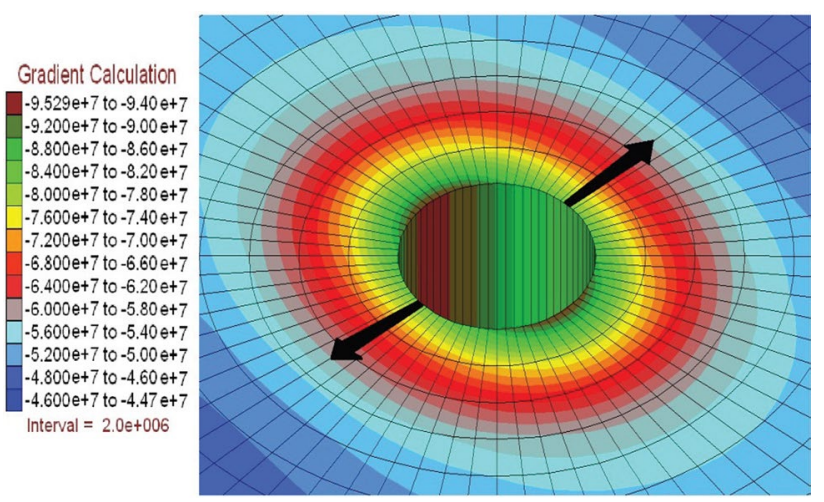

Fig. 7 To form a hydraulic fracture based on the distribution of tensions around the well

using the discrete element method. As shown in Fig. 8, in this simulation, only the natural fractures around the well that are connected to each other and form a natural fracture are shown.

The discrete element method is a two-dimensional numerical analysis method that is developed for the analysis of the rock mechanics of discontinuous environments.

In Fig. 9, the natural fracture situation around the well is simulated using this method.

As can be seen, in this simulation only the natural fractures around the well that are connected to each other and form a natural fracture are shown. In other words, in areas where there is no natural fracture, there is a possibility that the fracture is separate and there is no connection to another natural fracture. The proposed model is a two-dimensional model that consists of a $8 \times 8 \mathrm{~m}$ block in two $X$ and $Y$, and the well is located in the middle of the block.

It is assumed that the hydraulic fracture is applied only to the optimum layer and all parameters are constant and the only parameter that can be changed is the length of the hydraulic fracture, its direction and its opening. Four nodes are defined in the well, with two nodes on the ceiling and two nodes in the wall to measure the flow rate of the fluid into the well. The data used in this model are obtained by plotting wells and corrugations. The most basic of these data is given in Table 1 .

The flow state of the fluid in the fractures is shown in Fig. 9. This figure only shows the major flows in the more permeable fracture. Fluid flow is present in all of the slots, but only large flows have been shown here. In Fig. 10, it can also be seen that the flow of fluids in the fractures is large.

The PKN model is used to propagate the hydraulic fracture. In this model, the length of the hydraulic fracture is assumed to be much greater than the height or opening of the natural fracture. The created fracture has a constant height independent of the length of the fracture. As noted, the

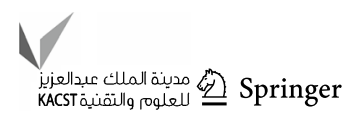



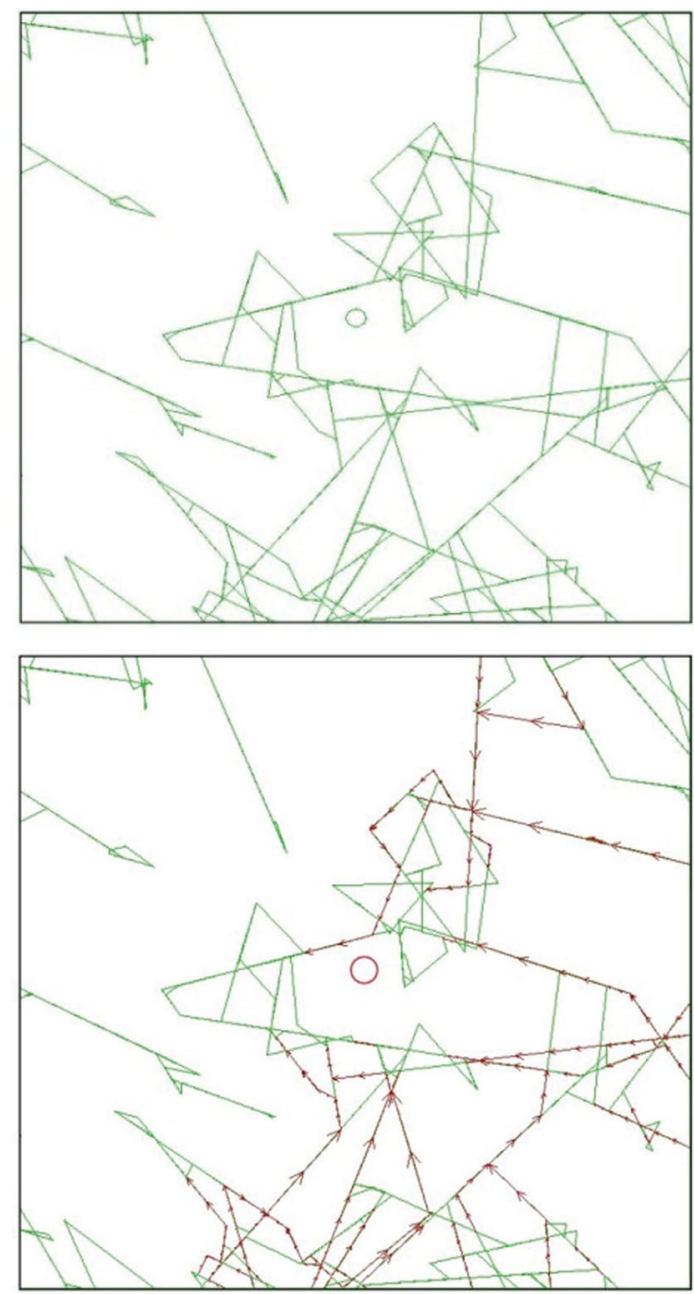

Fig. 8 Location of fractures and currents around them

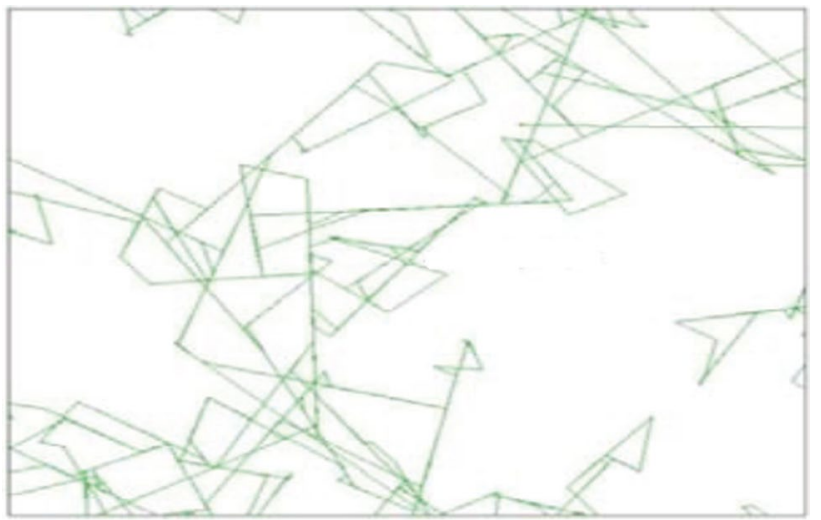

Fig. 9 Status and location of natural fractures around the well

characteristics of the reservoir including natural fractures, wells, and stone particles are listed in Table 1. Accordingly, the hydraulic fracture is created in the specified direction.
Table 1 Data used in the discrete element method

Public data

size of the selected block

$8 \times 8 \mathrm{~m}$

Well diameter

$8.5 \mathrm{In}$.

Reservoir fluid density

$21 \mathrm{~kg} / \mathrm{m}^{3}$

Compressibility

Intact rock properties

$1 \mathrm{e}^{6}{ }_{\mathrm{psi}-1}$

Density

$1900 \mathrm{~kg} / \mathrm{m}^{3}$

Shear modulus

$21 \mathrm{e}^{9}$

Properties of natural fractures

Average hardness

Displace-

ment/tension) $\mathrm{e}^{9}$

Average deflection angle

$30^{\circ}$

Average permeability

$100 \mathrm{mD}$

Structural model

Columbus

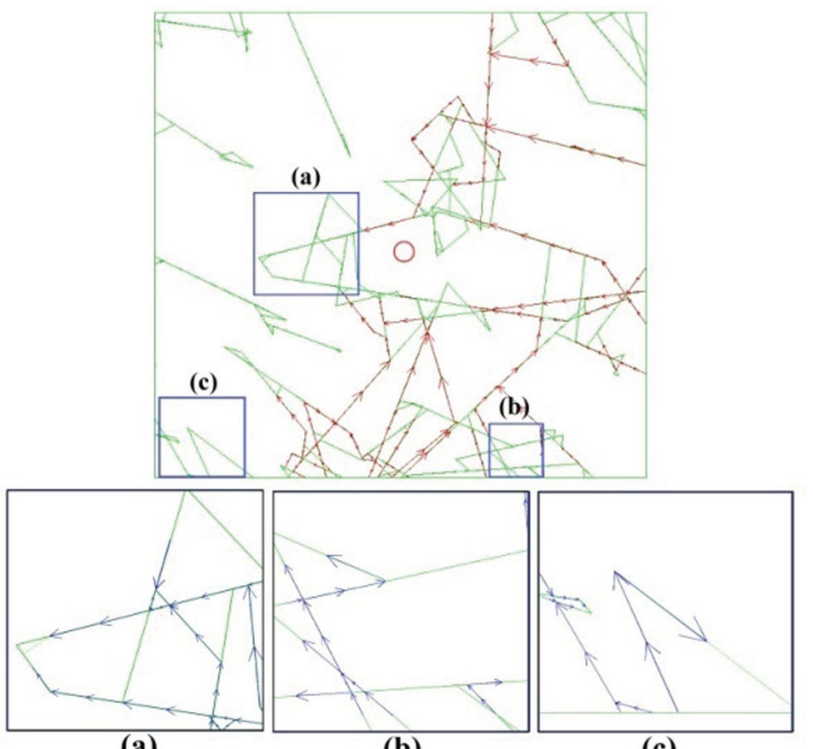

(a)

(b)

(c)

Fig. 10 Small currents in low-permeability fractures

The fracture length increases at each step; that is, at first a fracture of $2 \mathrm{~m}$ is created; in the next step, the fracture is $4 \mathrm{~m}$ long, and this process continues until we reach a fracture of $20 \mathrm{~m}$, which is actually equal to the dimensions of the block. These steps can be seen in Fig. 11.

The hydraulic fracture is shown in Figs when it is connected to the fracture. For example, in Fig. 11, when the length of the hydraulic fracture is $2 \mathrm{~m}$, there is no fracture in the shape; because the fracture with this length does not cut another fracture or is not connected to the fracture. When the length of the hydraulic fracture is $16 \mathrm{~ms}$, its length increases below; because it connects to other fractures, and because it does not bond to the fracture, it does not extend on the other 
Fig. 11 Hydraulic fracture applied with different lengths
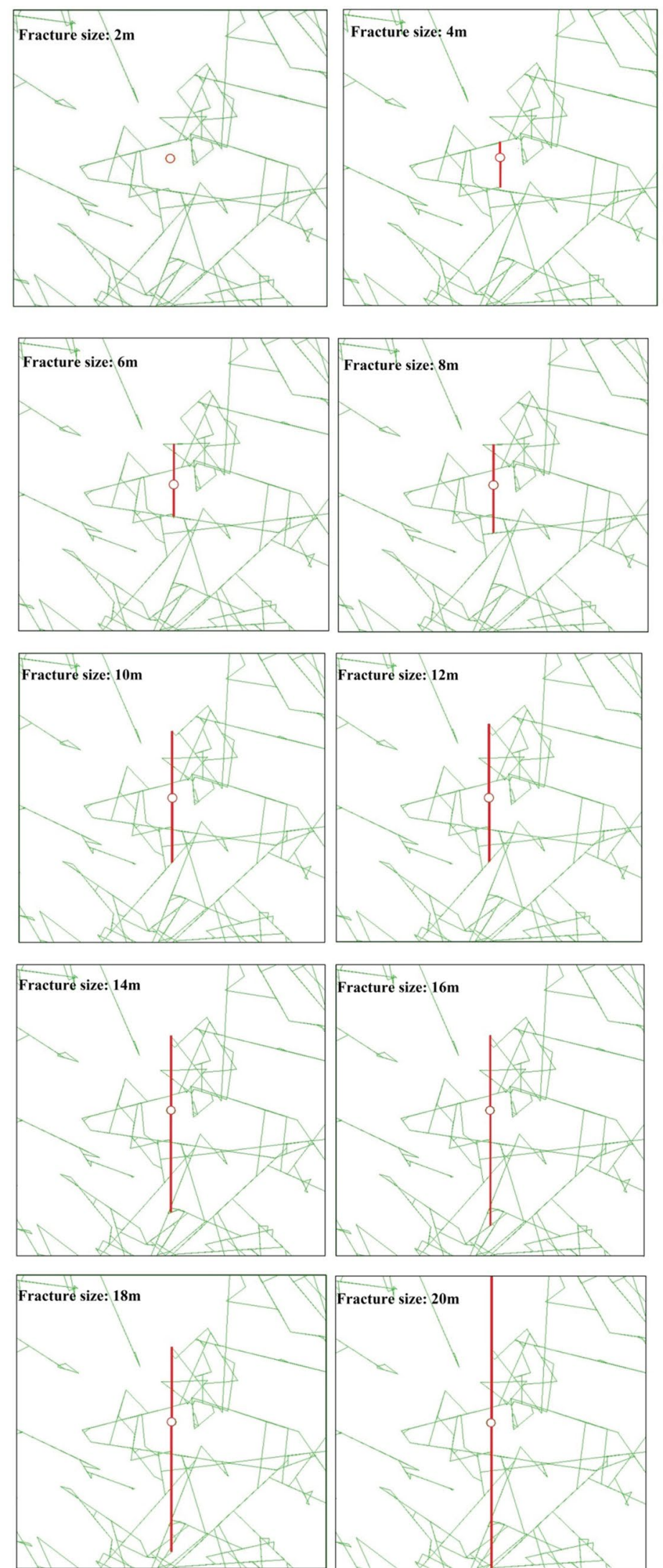
part, i.e., the upper part of the fracture. Therefore, the extension of the fracture does not increase in shape.

It is assumed that the hydraulic fracture is applied only to the layer, all the factors are constant and the only variable that can be changed is the length of the hydraulic fracture, its direction and its opening. Based on the distribution of stresses around the well, the hydraulic fracture is in a $90^{\circ}$ direction.

Carefully, in the form (Fig. 12), we find that half of the hydraulic fracture extends from an area that is characterized by a large accumulation of natural fractures.

But half the other, the hydraulic fracture passes through a section where there are few natural fractures. The production chart also shows that by increasing the length and height of the hydraulic fracture, the production will have an acceptable change. In Fig. 13, a section of the hydraulic fracture that is in contact with more natural fractures is shown.

It can be deduced from the figure that a large flow of natural fractures enters the hydraulic fracture, which may be due to the cutting of these fractures by a hydraulic fracture. But in the other half the hydraulic fracture is not in this situation; that is, the cutting of natural fractures is not a factor in increasing production, but the fractures coalescence and has

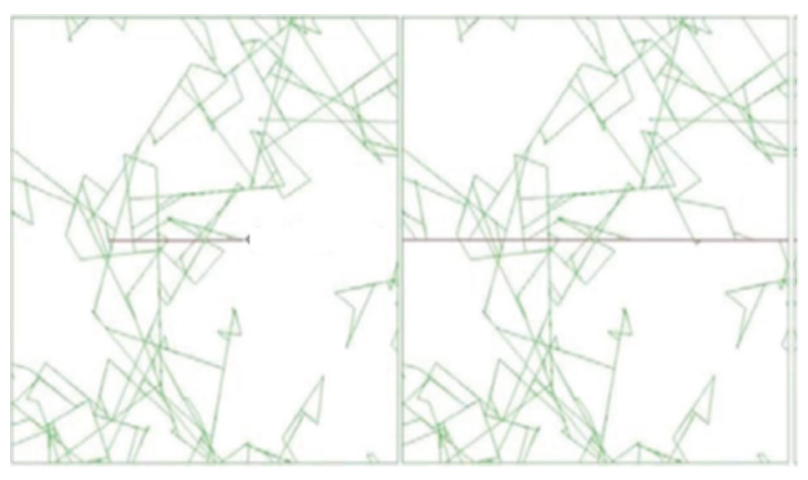

Fig. 12 Hydraulic fracture operations $90^{\circ}$ in two different sizes

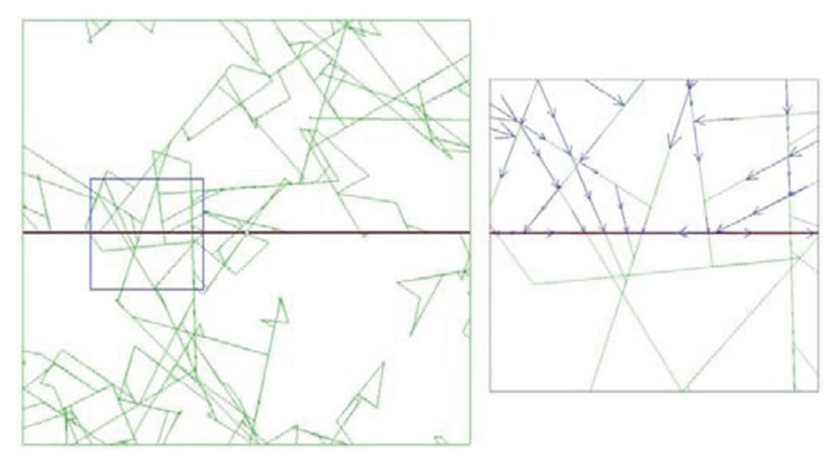

Fig. 13 A section of the hydraulic gap in an area where cutting of natural gaps is a major factor in increasing production a more significant role. As shown in Fig. 14, in this region, coalescence caused the connection of natural fractures with hydraulic fracture and led to increased production.

Based on the production rates, if the height of the hydraulic fracture increases, it will be economically justified to have more natural fractures in the hydraulic fracture.

Figure 15 shows the production rate in the case of a hydraulic fracture with different lengths.

The production rate is based on the two nodes on the ceiling and the other two nodes in the well wall, and the total flow of these nodes is equal to the total production rate. Figure 16 shows the phenomenon of coalescence fracture for a $6 \mathrm{~m}$ long hydraulic fracture.

Here are two small fractures connected to a hydraulic fracture that is applied at a length of $6 \mathrm{~m}$. Typically, by increasing the fracture length, the number of fractures that are cut off by the hydraulic fracture is increased. On the other hand, the probability of coalescence of the fractures is also increased. With increasing hydraulic fracture length, from $8 \mathrm{~m}$ to $10 \mathrm{~m}$ and further to $12 \mathrm{~m}$, the production rate decreases instead of increasing as shown in Fig. 17, in reverse $\mathrm{b}$ and $\mathrm{c}$ sections.

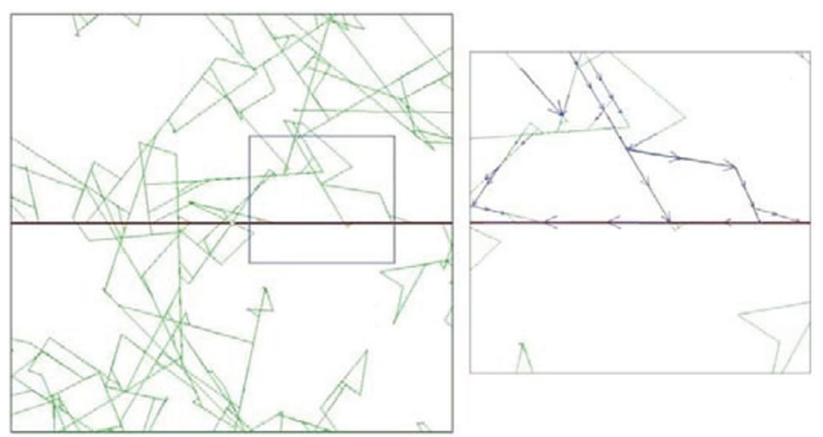

Fig. 14 Part of the hydraulic fracture in the area where the coalescence of the main factor of production

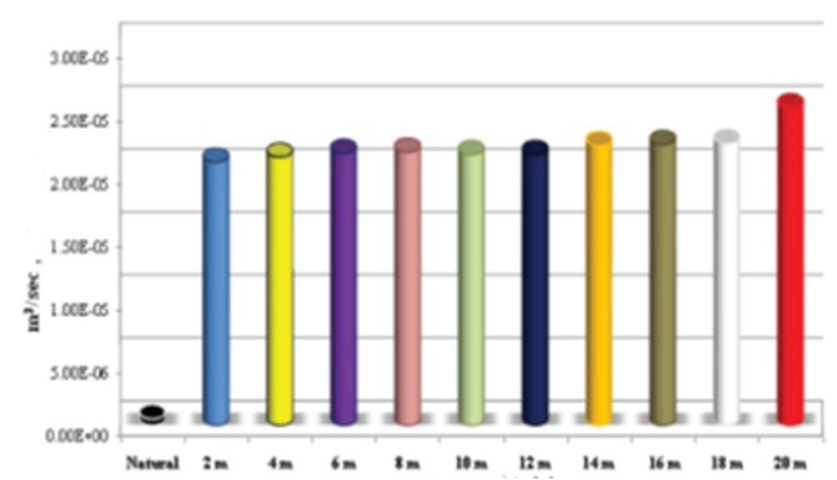

Fig. 15 Production rate in normal conditions and hydraulic fracture with different lengths 


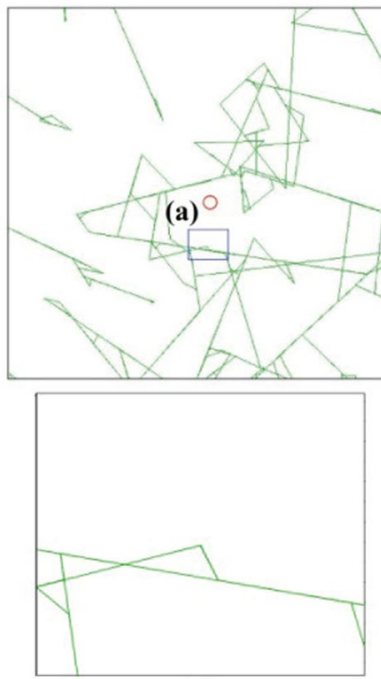

(a)
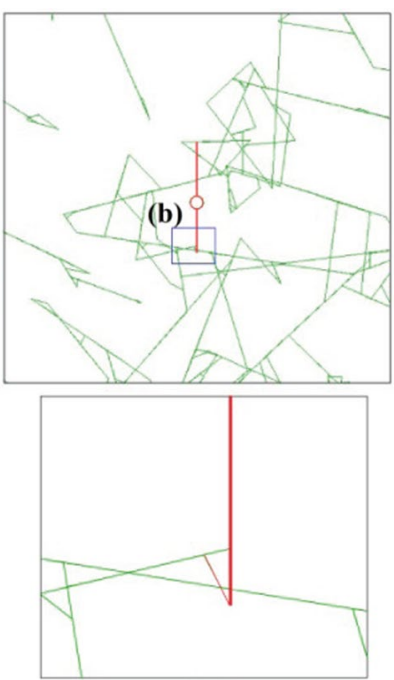

(b)
Fig. 16 The phenomenon of coalescence fractures in a $6 \mathrm{~m}$ long hydraulic fracture

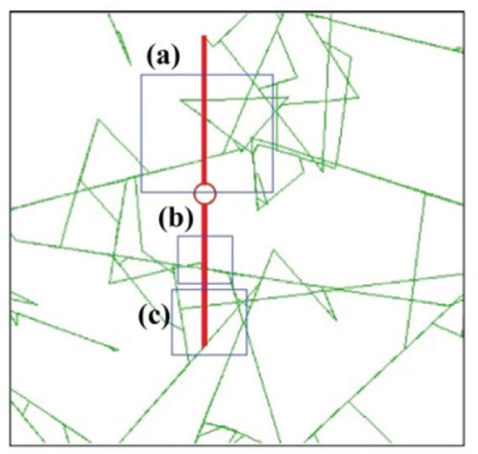

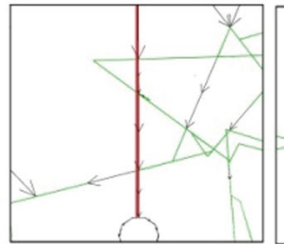

(a)

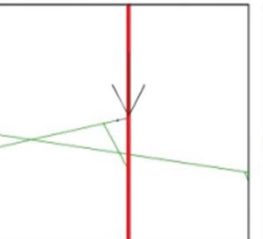

(b)

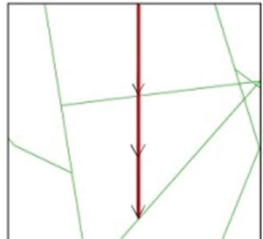

(c)
Fig. 17 Fluid flow conditions in sections of hydraulic fractures of 10 and $12 \mathrm{~m}$ in length

This means that by connecting the hydraulic fracture to the fracture that is shown in the figure, it is natural to flow from the hydraulic fracture to the fracture. The reason for this reduction in production is that, by connecting the hydraulic fracture to this fracture, the fluid flows into the slot instead of entering the well through the hydraulic fracture. The same situation will be established for a 12-m-long hydraulic fracture; because in the section where the flow enters the fracture, with a fracture lengthening of 10 to $12 \mathrm{~m}$, the hydraulic fracture is not bonded to the fracture.

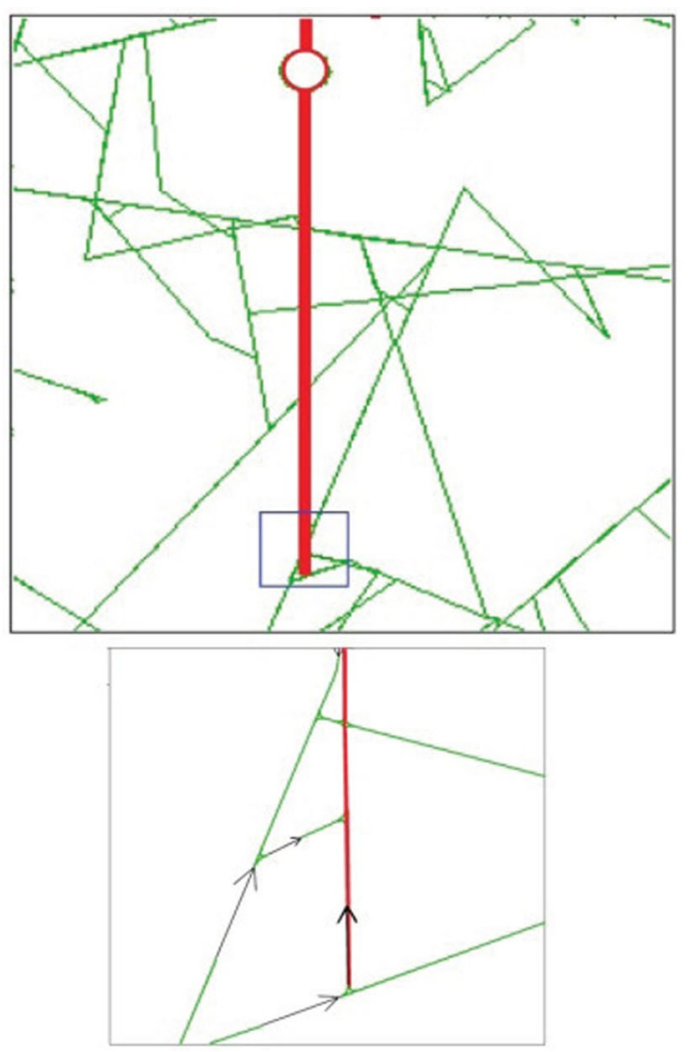

Fig. 18 Current status in a section of the hydraulic fracture of $14 \mathrm{~m}$ in length

To ensure this analysis, a hydraulic fracture of $14 \mathrm{~m}$ in length is also being examined. As shown in Fig. 18, the flow into the hydraulic fracture is in fact one of the main and big flows.

Therefore, the reason for the increase in production can be indicated by the fact that when a hydraulic fracture with a length of $14 \mathrm{~m}$ is applied, this fracture is connected to fractures that have high permeability and have a main and big flow that causes the flow to be neutralized from the hydraulic fracture to the fracture in the studied section and leads to increased production.

\section{Conclusion}

In this study, the performance of hydraulic fracture was investigated in one of the Iraqi gas field discharged reservoirs. For this purpose, two numerical methods of separate element and developed finite difference were used. In a separate element method, the development of hydraulic fracture was simulated in a fractured environment. The results obtained in this paper can be summarized as follows:

Based on variation of length and height of hydraulic fracture in this method, in cases where the density of natural 
fractures is low, an increase in length is acceptable and in cases where the density of natural fractures is high, the increase in production is logical seems to be logical; because when the hydraulic fracture is slightly associated with natural fractures, increasing the length of the hydraulic fracture compared to the height increase has a more visible effect on the production and conversely, when the hydraulic fracture is located in areas with high natural fractures, Increasing the height of the hydraulic fracture will affect production more. The criterion in this case is the amount of production.

In the numerical finite difference method developed, the interaction of hydraulic fracture with natural fractures was simulated $\left(45^{\circ}\right)$. The growing hydraulic fracture has exerted a high pressure on natural fractures, causing them to be cut off before they reach the hydraulic fracture to the natural fractures. It has the effect of creating an open area in natural fractures. Tensile and shear joints before and after the hydraulic fracture to the natural fracture were evaluated. It was observed that the coalescence between the fracture and the natural fracture would be different and the degree of opening would be different.

In this study, hydraulic fracture operation with different lengths in a naturally fractured gas reservoir was investigated. In naturally fractured gas reservoirs, the production rate is usually increased by increasing the length of the hydraulic fracture. But this depends on the number of broken fractures and the induction of fractures. If the hydraulic fracture does not connect to the natural fractures in which the main flows are flowing, it cannot increase production as expected; so that if this length of the hydraulic fracture is designed to end with natural fractures that contribute little or insignificantly to the fluid flow in the reservoir (that is, natural fractures with low permeability), this will even change the direction of flow and reduce production. Therefore, determining the length of the fracture that can end the natural fractures with the main currents is very important in designing hydraulic fracturing operations.

When the hydraulic fracture is applied to such a fracture with natural fractures, complex interactions occur between the hydraulic fracture and natural fractures. Increasing the length of the hydraulic fracture was observed in naturally fractured reservoirs; but due to the fact that in the interaction between the hydraulic fracture with the natural fracture was the reverse suction phenomenon, this increase was discontinuous. Depending on the natural fracture, this phenomenon affected the production and reduced its production.

Considering that using the distribution of principal stresses or induced stresses around the well, one can determine the direction in which the hydraulic fracture occurs. In this study, this work was carried out using Finite Difference Method. Therefore, depending on which fracture occurs and are there any natural fractures with the main flows in the fracture, the economic performance of the hydraulic fracture and the production rate are predictable. Of course, in the hydraulic fracture operation, the process of fractures coalescence should also be taken into account; because it can either increase or decrease production. The optimum hydraulic fracture action can be considered when the main fractures with large currents are in the same direction as the hydraulic fracture, so that the hydraulic fracture can connect these natural fractures to the well.

Open Access This article is licensed under a Creative Commons Attribution 4.0 International License, which permits use, sharing, adaptation, distribution and reproduction in any medium or format, as long as you give appropriate credit to the original author(s) and the source, provide a link to the Creative Commons licence, and indicate if changes were made. The images or other third party material in this article are included in the article's Creative Commons licence, unless indicated otherwise in a credit line to the material. If material is not included in the article's Creative Commons licence and your intended use is not permitted by statutory regulation or exceeds the permitted use, you will need to obtain permission directly from the copyright holder. To view a copy of this licence, visit http://creativecommons.org/licenses/by/4.0/.

\section{References}

Bennion D, Thomas F, Bietz R (1996) Low permeability gas reservoirs: problems, opportunities and solutions for drilling, completion, stimulation and production. In: SPE gas technology symposium, 35577. https://doi.org/10.2118/35577-MS

Benson PM (2004) Experimental study of void space, permeability and elastic anisotropy in crustal rocks under ambient and hydrostatic pressure. Ph.D. Thesis, University College London. Preprint at. http://discovery.ucl.ac.uk/1446540

Benson PM, Vinciguerra S, Meredith PG, Young RP (2010) Spatiotemporal evolution of coupled hydro-mechanical seismicity: a laboratory study. Earth Planet Sci Lett 297:315-323

Bernier F et al (2007) Fractures and self-healing within the excavation disturbed zone in clays (SELFRAC). Final report to European Commission (Project FIKW-CT2001-00182) Preprint at. www. euridice.be/sites/default/files/scientific/SELFRAC\%20final\%20 report.pdf. Accessed 2007

David CJ et al (2018) $\mathrm{KG}^{2} \mathrm{~B}$, a collaborative benchmarking exercise for estimating the permeability of the Grimsel granodiorite-part 1: measurements, pressure dependence and pore fluid effects. Geophys J Int 215:799-824

Davy CA et al (2007) Permeability of macro-cracked argillite under confinement: gas and water testing. Phys Chem Earth 32:667-680

Fazio M, Benson PM, Vinciguerra SV (2017) On the generation mechanisms of fluid-driven seismic signals related to volcanotectonics. Geophys Res Lett 44:734-742

Gandossi L (2013) An overview of hydraulic fracturing and other formation stimulation technologies for shale gas production. In: European Commission Joint Research Centre Institute for energy and transport technical reports, 26347, https://doi. org/10.2790/99937

Gehne S (2018) A laboratory study of fluid-driven tensile fracturing in anisotropic rocks. Ph.D. Thesis, University of Portsmouth. Preprint at. https://ethos.bl.uk/OrderDetails.do?uin=uk.bl.ethos .765705

Gehne S, Benson PM (2017) Permeability and permeability anisotropy in Crab Orchard sandstone: experimental insights into spatiotemporal effects. Tectonophysics 712:589-599 
Goodfellow SD et al (2015) Hydraulic fracture energy budget: insights from the laboratory. Geophys Res Lett 42:3179-3187. https://doi. org/10.1002/2015GL063093

Gudmundsson A, Brenner SL (2001) How hydrofractures become arrested. Terra Nova 13:456-462

Guo T et al (2013) Experimental study of fracture permeability for stimulated reservoir volume (SRV) in shale formation. Transp Porous Med 98:525-542

Hahn R, Bartosik M, Soler R, Kirchlechner C, Dehm D, Mayrhofer PH (2016) Superlattice effect for enhanced fracture toughness of hard coatings. Scripta Materialia 124:67-70. https://doi.org/10.1016/j. scriptamat.2016.06.030

Jones C, Meredith P, Ayling MR (1998) An experimental study of elastic wave propagation anisotropy and permeability anisotropy in an illitic shale. In: SPE/ISRM rock mechanics in petroleum engineering, 47369. https://doi.org/10.2118/47369-MS

Kassis S, Sondergeld CH (2010) Fracture permeability of gas shale: effect of roughness, fracture offset, proppant, and effective stress. In: SPE international oil and gas conference and exhibition in China, 131376. https://doi.org/10.2523/131376-MS

Kneafsey TJ et al (2018) An overview of the EGS Collab project: Field validation of coupled process modeling of fracturing and fluid Flow at the Sanford Underground Research Facility. 43rd Workshop on Geothermal Reservoir Engineering, Stanford University, paper SGP-TR-213. Preprint at. https://pangea.stanford.edu/ERE/ pdf/IGAstandard/SGW/2018/Kneafsey.pdf

Kranz R et al (1979) The permeability of whole and jointed Barre granite. Int J Rock Mech Min Sci Geomech Abstr 16:225-234

Law B, Curtis J (2002) Introduction to unconventional petroleum systems. Am Assoc of Pet Geol 86:1851-1852

Ma L et al (2016) Novel 3D centimetre-to nano-scale quantification of an organic-rich mudstone: the Carboniferous Bowland Shale, Northern England. Mar Pet Geol 72:193-205

Malhotra S, Rijken P, Sanchez A (2018) Experimental Investigation of Propellant Fracturing in a Large Sandstone Block. SPE Drilling Completion 33(02):87-99. https://doi.org/10.2118/191132-PA

Montgomery CT, Smith MB (2010) Hydraulic fracturing: history of an enduring technology. J Pet Technol 62:26-40

Nygord R et al (2006) Brittle-ductile transition, shear failure and leakage in shales and mudrocks. Mar Pet Geol 23:201-212

Pang W, Du J, Zhang T, Ehlig-Economides CA (2016) Actual and Optimal Hydraulic-Fracture Design in a Tight Gas Reservoir. SPE Prod Oper 31(1):60-68. https://doi.org/10.2118/168613-PA
Reinicke A et al (2010) Hydraulic fracturing stimulation techniques and formation damage mechanisms-Implications from laboratory testing of tight sandstone-proppant systems. Chemie der Erde-Geochemistry 70:107-117

Rubin AM (1993) Tensile fracture of rock at high confining pressure: implications for dike propagation. J Geophys Res 98:15919-15935

Sammonds P (1999) Understanding the fundamental physics governing the evolution and dynamics of the Earth's crust and ice sheets. Philos Trans R Soc Lond A Math Phys Eng Sci 357:3377-3401

Stanchits $S$ et al (2011) Fracturing of porous rock induced by fluid injection. Tectonophysics 503:129-145

Tan Y et al (2018) Laboratory study of proppant on shale fracture permeability and compressibility. Fuel 222:83-97

Tuffen H, Dingwell D (2005) Fault textures in volcanic conduits: evidence for seismic trigger mechanisms during silicic eruptions. Bull Volcanol 67:370-387

Vinciguerra S, Meredith PG, Hazzard J (2004) Experimental and modeling study of fluid pressure-driven fractures in Darley Dale sandstone. Geophys Res Lett 31:L09609. https://doi. org/10.1029/2004GL019638

Walsh J (1981) Effect of pore pressure and confining pressure on fracture permeability. Int J Rock Mech Min Sci Geomech Abstr 18:429-435

Wang Q et al (2014) Natural gas from shale formation-the evolution, evidences and challenges of shale gas revolution in United States. Renew Sustain Energy Rev 30:1-28

Wei Y, Economides MJ (2005) Transverse Hydraulic Fractures From a Horizontal Well. SPE Ann Tech Conf Exhib. https://doi. org/10.2523/94671-MS

Zhang J et al (2013) Laboratory measurement of hydraulic fracture conductivities in the Barnett shale. In: International petroleum technology conference, 16444. https://doi.org/10.2523/IPTC16444-MS

Zoback M et al (1977) Laboratory hydraulic fracturing experiments in intact and pre-fractured rock. Int J Rock Mech Min Sci Geomech Abstr 14:49-58

Publisher's note Springer Nature remains neutral with regard to jurisdictional claims in published maps and institutional affiliations. 